\title{
Nestmate Recognition and Incompatibility Between Colonies of the Acacia-Ant Pseudomyrmex Ferruginea
}

\author{
Alex Mintzer \\ Museum of Zoology and Division of Biological Sciences, The University of Michigan, Ann Arbor, Michigan 48109, USA
}

Received September 27, 1981 / Accepted February 12, 1982

Summary. 1. Compatibility between workers of 21 different colonies of the acacia-ant Pseudomyrmex ferruginea was examined. The colonies were reared from foundress queens in the greenhouse, on a clone of Acacia hindsii. Widespread incompatibility between colonies was encountered in these tests. Since diet and nesting environment are uniform, these results strongly suggest that the ants are producing recognition pheromones.

2. Worker brood from a stock colony was separated into groups of larvae and pupae, and each group was reared by a different foster reproductive female. The absence of antagonistic reactions between workers reared in the different groups indicates that the reproductive females are not the direct source of colony recognition pheromones.

\section{Introduction}

The ability of many social insects to discriminate nestmates from other conspecifics is well documented (Barrows et al. 1975; Fielde 1903, 1904; Free 1958; Greenberg 1979; Kalmus and Ribbands 1952; Hölldobler and Michener 1980). Strongly antagonistic reactions toward non-nestmates will affect patterns of interference competition and nest distributions. If nestmates are usually close genetic relatives, their recognition is obviously relevant to kin-selection theory.

Ants use olfactory cues to distinguish nestmates from other conspecifics (Wilson 1971). The implied odor differences may be due to (1) diet and nesting environment and (2) colony recognition pheromones produced by the ants.

The ants most likely to produce their own recognition pheromones are those living in uniform environments which fail to supply diverse or heterogeneous olfactory cues. Pseudomyrmex ferruginea is an obligate inhabitant of the swollen-thorn acacias of low- land Central America. The ants nest only in the acacia thorns, and their diet consists primarily of two plant products, foliar nectar and Beltian bodies (Janzen 1966, 1967). Janzen described intense aggressive encounters between colonies in the field. These observations suggest that the ants may rely heavily on colony recognition pheromones to distinguish nestmates.

To investigate the nestmate recognition capabilities of $P$. ferruginea, I utilized laboratory colonies reared from foundress females on an acacia clone. Compatibility between laboratory colonies was examined. The present study was designed to (1) look for nestmate recognition in a homogeneous environment and (2) investigate the role of the reproductive female (gyne) in the production of intercolony odor differences.

\section{Materials and Methods}

Establishment of the Laboratory Population. Clonal rootstock of Acacia hindsii was collected in Nayarit, Mexico. This swollen-thorn acacia produces dense thickets as a result of sucker shoot development from a shallow lateral root system. The stump rootstock was potted in four large community tubs, yielding three to six shoots per tub. The plants were established at the University of Michigan Botanical Gardens in May 1978. Vegetative propagation of green stem cuttings greatly increased the available greenhouse plant population.

Colony-founding females of Pseudomyrmex ferruginea were collected in San Luis Potosi and Tamaulipas, Mexico, in May 1979. At six widely spaced localities ( $>8 \mathrm{~km}$ apart) along highways and local roads, thorns with females inside were collected from small plants without established colonies. These thorns were attached to the greenhouse plants, and the base of each shoot was coated with a Tanglefoot band. In late August, surviving small colonies were isolated on separate branches with Tanglefoot bands. Subsequently, colonies were moved onto individual shoots wherever possible, until all shoots were occupied. Adjacent shoots were pruned and cut back as needed to prevent leaf contact between them.

Worker Compatibility Tests Between Colonies. Twenty-one colonies were used in compatibility tests. Colonies with at least 12 occupied 
thorns and at least 100 workers were selected. Short branch segments, consisting of two ant-oceupied thorns and the basal internode, were cut from each tested plant and were stripped of side branches or leaves. The branches were placed on a stand under red illumination for the tests, and resident and nonresident ants were introduced on the branch exterior. The introduced ants were collected on the exterior surfaces of occupied plants.

Each test lasted $5 \mathrm{~min}$. The resident ants usually remained inside the thorns, and introduced ants searched for the thorn entrance. At the entrance, the introduced ant was either admitted, denied entry, or attacked. Ants which were attacked or denied entry over a $5 \mathrm{~min}$ period were classified as rejected. Thorns which admitted ants were monitored for a period of 24-36 h after the test to detect delayed ejection of ants, and if no ants were ejected during this period, tests were classified as acceptances.

At the conclusion of each test and subsequent observation period, the test branch was either dissected or returned to the host colony to be used again. Each paired combination of recipient colonies and donor colonies was usually tested twice. One to three additional replications were conducted in some cases, to re-examine conditional acceptances and ambiguous results. At the conclusion of all tests, the laboratory colonies were examined to determine if the founding gyne was still present.

Tests for Colony Odor Production by the Reproductive Female. Four colony-founding gynes with definitive worker brood (prepupae and pupae) were obtained. This brood was discarded, and each gyne was placed in a separate branch containing three empty thorns, with tips opened to allow examination and manipulation of the contents.

Approximately 400 worker pupae and larvae were removed from each of two established lab colonies. One or two days later, each brood stock was divided into four batches, each consisting of about 90 immatures plus 4-6 newly emerged callow workers. Each of two batches of brood stock was placed with a separate gyne in thorns on her branch; the other two batches were placed in empty thorns on similar branches, without an adoptive gyne. In every case, the female and the introduced worker force accepted one another.

Compatibility tests were conducted between workers from these adoptive colony units after the first adopted worker was one month old, and before the females' own offspring reached the pupal stage. Two nestmate workers and one non-nestmate worker were introduced onto a short branch consisting of two unopened thorns from an unoccupied plant, placed on the stand for the $5 \mathrm{~min}$ test. Interactions with the non-nestmate were noted, with particular attention to behaviors which are atypical or infrequent among nestmates. The following behaviors (listed in order of increasing intensity) were observed and counted during the tests: allogrooming, directed antennal contact (beyond the routine 'greeting'), antennal contact with mandibles agape, chases and dodges after physical contact, grabbing or dragging, and fighting.

\section{Results}

Three of the experimental colonies were lost during the study period when they were attacked by ants from neighboring colonies. Fighting between colonies was similar to that described by Janzen (1973); workers fought individually, usually attempting to sting each other. Fighting pairs usually fell off the plant, resulting in a large accumulation of dead and injured ants under the plant.
Dissection of colonies at the conclusion of tests showed that the reproductive female was absent in four of the 18 remaining colonies. The number of workers ranged from about 500 to 4,000 per colony, and eggs and other brood stages were abundant in all dissected colonies.

\section{Compatibility Tests}

In 799 tests with introduced non-nestmates, 549 ants $(68.7 \%)$ were rejected by the recipient colony. Of the rejected ants, 243 were ejected from the test branch during the observation period following the initial 5 min test. Most colonies rejected $60 \%$ or more of the introduced nonresidents; rejected ants were often killed or dismembered, and fighting pairs were observed on many occasions. Not surprisingly, introduced nestmates were accepted. When considered as recipients, different colonies showed quite different rejection frequencies towards introduced non-nestmates $(\mathrm{SD}=19 \%)$. When the colonies were considered as sources of introduced ants, different colonies showed less variation in the frequency with which they encountered rejection ( $\mathrm{SD}=9.5 \%$ ).

The results of the $21 \times 21$ colony compatibility tests are shown in Table 1. Apparent acceptances are widely scattered across the compatibility table. Only two cases of complete bidirectional acceptance were observed $(\mathrm{NAM} 1 \rightleftharpoons \mathrm{NM} 4 ; \mathrm{NAM} 6 \rightleftharpoons \mathrm{SM} 2)$; several other unidirectional acceptances (e.g. NAM2 $\rightarrow$ LL1) were noted. Forty-eight test branches which did not reject test ants were dissected, and fighting ants were found inside the thorns on three occasions. In all other cases, all ants were together without fighting inside the thorns.

The frequency of rejection among colonies founded by females collected at the same locality did not differ significantly from that among colonies from different source localities. The rejection frequency between colonies occupying shoots within a tub was not significantly less than the rejection rate between tubs.

\section{Role of Reproductive Female}

Introduced ants from colonies without a reproductive female were rejected as often as those from queenright colonies $(73.5$ vs $68.0 \% ; z=1.12, P>0.05)$. Colonies without reproductive females rejected nonresidents more frequently than colonies with a reproductive female did (79.6 vs $67.3 \% ; z=2.41, P<0.025$ ).

Reactions between sister workers reared in separate colony-units from late larval and pupal stages were observed infrequently ( $4.7 \%$ of 466 cases) and were almost invariably low-intensity (e.g. directed an- 
Table 1. Compatibility matrix for the 21 colonies tested. X both test ants rejected; $O$ both (all) test ants accepted; / test ants accepted and rejected; - colonies attacked by neighbors, eliminated during study. Superscripts: number of replications, if other than two

\begin{tabular}{|c|c|c|c|c|c|c|c|c|c|c|c|c|c|c|c|c|c|c|c|c|c|}
\hline \multirow{2}{*}{$\begin{array}{l}\text { Test } \\
\text { branch } \\
\text { recipient } \\
\text { colony }\end{array}$} & \multicolumn{21}{|c|}{ Introduced ant from } \\
\hline & $\sum_{\bar{Z}}^{\bar{z}}$ & $\overrightarrow{\tilde{A}}$ & $\begin{array}{l}\widetilde{W} \\
\tilde{w}\end{array}$ & $\sum_{z}^{m}$ & $\sum_{Z}^{Y}$ & $\underset{\Sigma}{\bar{z}}$ & $\sum_{Z}^{\mathfrak{Z}}$ & $\overrightarrow{\sum_{n}}$ & $\sum_{Z}^{J}$ & $\bar{\Xi}$ & $\sum_{3}$ & $\sum_{z}^{\infty}$ & 羿 & $\tilde{D}$ & 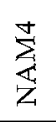 & $\stackrel{3}{3}$ & $\sum_{2}^{n}$ & $\sum_{z}^{\infty}$ & 志 & $\sum_{z}^{\infty}$ & $\sum_{i s}^{N}$ \\
\hline NM1 & $\mathrm{O}$ & $x$ & $\mathrm{X}$ & $\mathrm{X}$ & $X$ & $\mathrm{X}$ & $\mathrm{X}$ & $\mathrm{X}$ & $\mathrm{X}$ & $\mathrm{X}$ & $\mathrm{X}$ & 1 & $\mathrm{X}$ & $\mathrm{X}$ & $\mathrm{X}$ & $\mathrm{X}$ & 1 & $\mathrm{X}$ & $X$ & $\mathrm{X}$ & $\mathrm{X}$ \\
\hline ES1 & $i^{4}$ & $\mathrm{O}$ & $1^{4}$ & $\beta^{3}$ & $\mathrm{O}$ & $X^{3}$ & $\mathrm{X}$ & 1 & 1 & 1 & 1 & 1 & 1 & $\mathrm{X}$ & 1 & $\mathrm{X}$ & $x$ & $\mathrm{X}$ & $\mathrm{X}$ & $X$ & 1 \\
\hline $\mathrm{ES} 2$ & $i^{3}$ & $j^{4}$ & $\mathrm{O}$ & 1 & $1^{4}$ & $1^{4}$ & 1 & 1 & $\mathrm{O}$ & 1 & 1 & $\mathrm{X}$ & 1 & 1 & $\mathrm{X}$ & $\mathrm{X}$ & $X$ & $\mathrm{X}$ & $\mathrm{X}$ & $\mathrm{X}$ & $\mathrm{X}$ \\
\hline NM3 & $\mathrm{X}$ & $\mathrm{O}^{4}$ & $x$ & $\mathrm{O}$ & $x$ & $\mathrm{X}$ & 1 & $x$ & $\mathrm{X}$ & 1 & $\mathrm{X}$ & $\mathrm{X}$ & 1 & $\mathrm{X}$ & $\mathrm{X}$ & $X$ & $X$ & $\mathrm{X}$ & $\mathrm{X}$ & 1 & $\mathrm{X}$ \\
\hline $\mathrm{NM} 2$ & $\mathrm{X}$ & $\mathrm{X}$ & 1 & $\beta^{3}$ & $\mathrm{O}$ & $\mathrm{X}$ & $x$ & 1 & 1 & $x$ & $\mathrm{X}$ & $x^{1}$ & $X^{1}$ & - & - & - & - & $\ldots$ & - & - & - \\
\hline NAM 1 & 1 & $\mathrm{X}$ & 1 & 1 & 1 & $\mathrm{O}$ & 1 & 0 & $\mathrm{O}^{3}$ & 1 & 1 & 1 & 1 & $X$ & $\mathrm{X}$ & $\mathrm{X}$ & $x$ & $X$ & $\mathrm{X}$ & 1 & $X$ \\
\hline NAM2 & $\mathrm{X}$ & $X$ & $\mathrm{x}$ & $\mathrm{x}$ & i & $j^{3}$ & $\mathrm{O}$ & $X$ & 1 & $i^{3}$ & $X$ & 1 & 1 & $X$ & $X$ & $\mathrm{X}$ & $x$ & $X$ & $X$ & $\mathrm{X}$ & $x$ \\
\hline SM1 & $\mathrm{O}^{3}$ & $\mathrm{O}$ & $\mathrm{O}^{3}$ & 1 & 0 & 1 & 1 & $\mathrm{O}$ & 0 & ' & - & - & - & - & - & - & - & - & - & - & - \\
\hline NM4 & $X$ & $X$ & 1 & $X$ & $X$ & $\mathrm{O}^{3}$ & 1 & 1 & $\mathrm{O}$ & $X^{1}$ & $\mathrm{X}^{1}$ & - & - & - & - & - & - & - & - & - & - \\
\hline LL1 & $X$ & $p^{3}$ & $\mathrm{X}$ & $X$ & $X$ & $\mathrm{X}$ & $\mathrm{O}^{5}$ & 1 & $\mathrm{X}^{1}$ & 0 & $\beta^{3}$ & $\mathrm{x}$ & $\mathrm{O}^{5}$ & 1 & $\mathrm{X}$ & $X$ & 1 & $\mathrm{X}$ & $X$ & $x$ & $\mathrm{X}$ \\
\hline WNM & 1 & $1^{4}$ & 1 & 1 & 1 & $j^{7}$ & $1^{4}$ & - & - & $X$ & 0 & $X$ & $X$ & 1 & $\mathrm{X}$ & $X$ & $x$ & $\mathrm{X}$ & $\mathrm{X}$ & $X$ & $\mathrm{X}$ \\
\hline NAM3 & $\mathrm{X}$ & $\mathrm{X}$ & 1 & $X$ & $x^{1}$ & $\mathrm{X}$ & $\mathrm{X}$ & - & - & $\mathrm{X}$ & $X^{1}$ & $\mathrm{O}$ & 1 & $\mathrm{X}$ & $\mathrm{X}$ & $X$ & $\hat{x}$ & $\mathrm{X}$ & $\mathrm{X}$ & 1 & $\mathrm{X}$ \\
\hline $\mathrm{LL} 2$ & $\mathrm{X}$ & $p^{3}$ & 1 & $/^{4}$ & $\mathrm{O}^{1}$ & $X$ & $/^{6}$ & - & - & $\beta^{3}$ & 1 & $X$ & $\mathrm{O}$ & $X$ & $\mathrm{X}$ & $\mathrm{X}$ & $X$ & $X$ & $\mathrm{X}$ & $\mathrm{X}$ & 1 \\
\hline ES3 & $\mathrm{X}$ & $\mathrm{X}$ & $p^{3}$ & $\mathrm{X}$ & - & 1 & $\mathrm{X}$ & - & - & 1 & $p^{3}$ & $1^{3}$ & $X$ & $\mathrm{O}$ & 1 & $X$ & $\mathrm{X}$ & 1 & $X$ & $\mathrm{O}^{4}$ & $X$ \\
\hline NAM4 & $\mathrm{X}$ & $X$ & 1 & $\mathrm{X}$ & - & $\mathrm{X}$ & $j^{4}$ & - & - & $X$ & ${ }^{\prime} \mathrm{X}$ & $\mathrm{X}$ & $\mathrm{X}$ & $p^{3}$ & $\mathrm{O}$ & $X$ & 1 & $i$ & 1 & $X$ & $\mathrm{X}$ \\
\hline LL3 & $X$ & $X$ & 1 & $\mathrm{X}$ & - & $X$ & X & - & - & $\mathrm{X}$ & $X$ & $X$ & $x$ & $p^{3}$ & $\mathrm{X}$ & $\mathrm{O}$ & $X$ & $X$ & $X$ & $X$ & $X$ \\
\hline NAM 5 & $\mathrm{X}$ & 1 & 1 & $X$ & - & $\mathrm{X}$ & $\mathrm{X}$ & - & - & $\mathrm{X}$ & 1 & 1 & 1 & $\mathrm{O}^{4}$ & $\mathrm{O}^{4}$ & $/^{4}$ & 0 & 1 & 1 & 1 & 1 \\
\hline NM5 & $\mathrm{O}^{4}$ & $\mathrm{X}$ & $i$ & $\mathrm{X}$ & - & 1 & 1 & - & - & $p^{3}$ & 1 & 0 & $\mathrm{O}^{3}$ & $\beta^{3}$ & $\mathrm{O}^{3}$ & 1 & 0 & $\mathrm{O}$ & $p^{3}$ & $j$ & $X$ \\
\hline LL4 & $X$ & $X$ & 1 & $X$ & - & $X$ & $\mathrm{X}$ & - & - & 1 & $\mathrm{X}$ & 1 & $\mathrm{X}$ & $\mathrm{X}$ & 1 & $X$ & $X$ & $X$ & $\mathrm{O}$ & $\mathrm{X}$ & $\beta^{3}$ \\
\hline NAM6 & $1^{3}$ & 1 & $\mathrm{X}$ & $X$ & - & $\mathrm{X}$ & $X$ & - & - & 1 & $x$ & 1 & 1 & 1 & $\mathrm{O}^{3}$ & $\mathrm{O}^{3}$ & 1 & $\mathrm{O}^{3}$ & 1 & 0 & $\mathrm{O}^{3}$ \\
\hline SM2 & $\mathrm{X}$ & $\mathrm{X}$ & $X$ & $\mathrm{X}$ & - & $\mathrm{X}$ & 1 & -. & - & $\mathrm{X}$ & $x$ & $X$ & $\mathrm{X}$ & 1 & 1 & 1 & $\mathrm{X}$ & $\mathrm{O}^{3}$ & $\mathrm{X}$ & $\mathrm{O}^{3}$ & $\mathrm{O}$ \\
\hline
\end{tabular}

tennation, allogrooming). The presence of a fostering gyne in the colony-units did not affect the reaction frequency or intensity. Reactions between workers from separate stocks reared without a gyne were more frequent $(25 \%$ of 162 cases; $P<0.001)$ and included some higher intensity behaviors (e.g. chases, grabbing, and fights).

\section{Discussion}

The marked incompatibility between the Pseudomyrmex ferruginea colonies reared under uniform conditions in the greenhouse strongly suggests that the ants are producing colony recognition pheromones. The pheromone chemistry and glandular source are unknown at present; we do not know if the inferred polymorphism represents qualitative or quantitative differences (e.g. concentration) in pheromonal compounds. Obviously, the genetic system involved in odor production is also unknown. The olfactory polymorphism permits nestmate recognition by the 21 laboratory colonies with little evidence of "odor duplication' between colonies. The experiments detected only very antagonistic reactions towards introduced ants; the observed acceptances probably encompass some less intense reactions.
One potential method for the production and maintenance of distinct yet uniform colony odors is to restrict production of recognition pheromones to the reproductive female, with pheromones spread through the colony by grooming and trophallaxis, as has been demonstrated for caste-inhibitory pheromones in some social insects (Wilson 1971). However, $P$. ferruginea has not adopted this scheme; queenless colonies retain distinctive odors and their workers continue to reject and be rejected by nonresidents. This indicates that the reproductive female is neither the direct source of the colony-recognition pheromone(s), nor the source of pheromones required for the vigilance of workers towards nonresidents.

The observed specificity in the recognition capabilities of $P$. ferruginea under homogeneous conditions reflects an evolutionary history of repeated contacts between colonies. If the penalties for failure to eject or exclude nonresidents are trivial, colony-specific recognition may have limited selective advantage. For a $P$. ferruginea colony, the costs for admitting invading conspecifics to the thorn containing the reproductive female are not trivial; queens of invaded colonies are usually killed. The extreme antagonism of workers to foreign queens may have led to subsequent evolution of nestmate recognition involving 
workers, to prevent elimination of the reproductive female by occasional intruders.

Because $P$. ferruginea workers lay viable maledetermined eggs in the absence of the queen (Mintzer, unpublished data), a colony could be parasitized by unrelated invading workers which begin laying eggs. Because worker oviposition is probably inhibited by a reproductive female, this threat is most important to colony-units which have lost contact with their queen (i.e. due to isolation or her death), and may explain why colonies without queens continue to reject nonresidents.

Acknowledgements. I am greatly indebted to Carole Mintzer for assistance with the experiments, to Robert Henry (U-M Botanical Gardens) for help in culturing the ant-acacia system, and to Barry Pullen for assistance in collecting the original rootstock in Mexico. I thank W.D. Hamilton, R.D. Alexander, and T.E. Moore for their comments on the manuscript. This study was funded by a grant from the University of Michigan Graduate School and a Hinsdale Scholarship award from the U-M Museum of Zoology.

\section{References}

Barrows EM, Bell WJ, Michener CD (1975) Individual odor differences and their social functions in insects. Proc Natl Acad Sci USA $72: 2824$

Fielde AM (1903) Artificial mixed nests of ants. Biol Bull (Woods Hole) $5: 320$

Fielde AM (1904) Power of recognition among ants. Biol Bull (Woods Hole) $7: 227$

Free JB (1958) The defence of bumblebee colonies. Behaviour $12: 233$

Greenberg L (1979) Genetic component of bee odor in kin recognition. Science 206:1095

Hölldobler B, Michener CD (1980) Mechanisms of identification and discrimination in social Hymenoptera. In: Mark1 H (ed) Evolution of social behavior: Hypotheses and empirical tests. (Dahlem Konferenzen 1980). Verlag Chemie, Weinheim

Janzen DH (1966) Coevolution of mutualism between ants and acacias in Central America. Evolution 20:249

Janzen DH (1967) Interaction of a bull's horn acacia (Acacia cornigera) with an ant inhabitant (Pseudomyrmex ferruginea) in eastern Mexico. Univ Kansas Sci Bull 47:315

Janzen DH (1973) Evolution of polygynous obligate acacia-ants in western Mexico. J Anim Ecol 42:727

Kalmus H, Ribbands CR (1952) The origin of the odors by which honeybees distinguish their companions. Proc R Soc 140:50

Wilson EO (1971) The insect societies. Belknap, Harvard, p 548 